\title{
The rise and rise of renewable cities
}

\author{
Peter Newman ${ }^{*}$ \\ Curtin University Sustainability Policy Institute, Perth, Australia
}

Received: 16 April 2017 / Received in final form: 11 July 2017 / Accepted: 27 July 2017

\begin{abstract}
The decoupling of fossil fuels from growth in economic activity has been proceeding rapidly for most of the 21st century and is analysed globally in terms of structures and technologies for energy efficiency and for switching to renewable energy in the world's cities. This is leading to the decline of coal and oil. The evidence suggests that the changes are based on demand for the structures and technologies that are emerging, facilitating a disruptive process. The rise of renewable cities can therefore be expected to accelerate.
\end{abstract}

\section{Introduction}

The rise of renewable cities began in the 1990s but has accelerated in the 21 st century [1,2]. As shown below, both coal and oil have begun to fall in the nations of the world driven mostly by their cities as this is where growth and change is happening [3]. The question raised by this paper is whether the rise will continue and even accelerate.

The theory behind whether the rise in renewable cities is likely to continue or accelerate is partly left to economists who project the future based on the past [4] and more recently by those who see disruptive innovation as causing the future and thus leading to much accelerated change [5,6]. Disruptive innovation is caused by demand rather than supply. The costs of supply need to be competitive but may not be the cheapest option when people discover they want it for many reasons and this changes the whole system that the market is based around. An example often given by Christensen [5] is how small floppy discs outcompeted the larger discs which were cheaper per unit of memory storage but were not as convenient to carry; the system changed in response by developing the portable lap top computer. Disruptive innovations can surprise businesses who focus just on supply costs and they can go bankrupt whilst their product is still the cheapest and the whole structural system around them changes in response to the new demand. This is known as the "Kodak effect" due to the way Kodak chose not to develop their digital cameras as they saw them as too expensive.

This paper seeks to find evidence of whether the renewable city is being driven by disruptive innovations based on demand, as well as competitive costs of supply, leading to a whole system change. If it is so, then the rise in renewable cities is likely to continue and even accelerate based on demand for the structures and products of the renewable city at a surprising rate.

\footnotetext{
* e-mail: p.newman@curtin.edu.au
}

\section{The decoupling of economic growth and fossil fuels}

In 2017, the International Energy Agency confirmed that economic growth has been decoupling from greenhouse emissions and fossil fuels since the start of the 21st century and that this was now leading to the first drop in fossil fuel consumption and subsequent emissions [7]. How this relates to the rise of the renewable city is the focus of this paper. The mechanisms are first understood by looking at a range of national data as set out in Figure 1.

Denmark decoupled relatively from the 1990s but absolutely over the last 17 years and is typical of many European nations and cities. The US and Australia have been slower but have now decoupled relatively from the 2000s and absolutely over the past 5-9 years. China decoupled relatively from 2005 and absolutely over the past few years with coal whilst oil has plateaued. India has started relative decoupling in the past decade and may change to an absolute decline in fossil fuels as it is investing strongly in renewables and urban electric rail[11]. These trends suggest a global process - the rise of the renewable city - as outlined by Droege $[1,2]$; this appears to be occurring much faster than expected and invites the question as to whether it will accelerate [3].

\section{Mechanisms for the rise of the renewable city}

The mechanisms behind the decoupling of wealth and fossil fuels and the resulting rise of renewable cities are likely to be based around structural energy efficiencies and growth in renewables. Whether they are disruptive, demand driven changes, will be examined with coal and oil. 


\section{Decoupling Wealth (GNI) from Fossil Fuels (coal and oil) indexed $1990=100$}
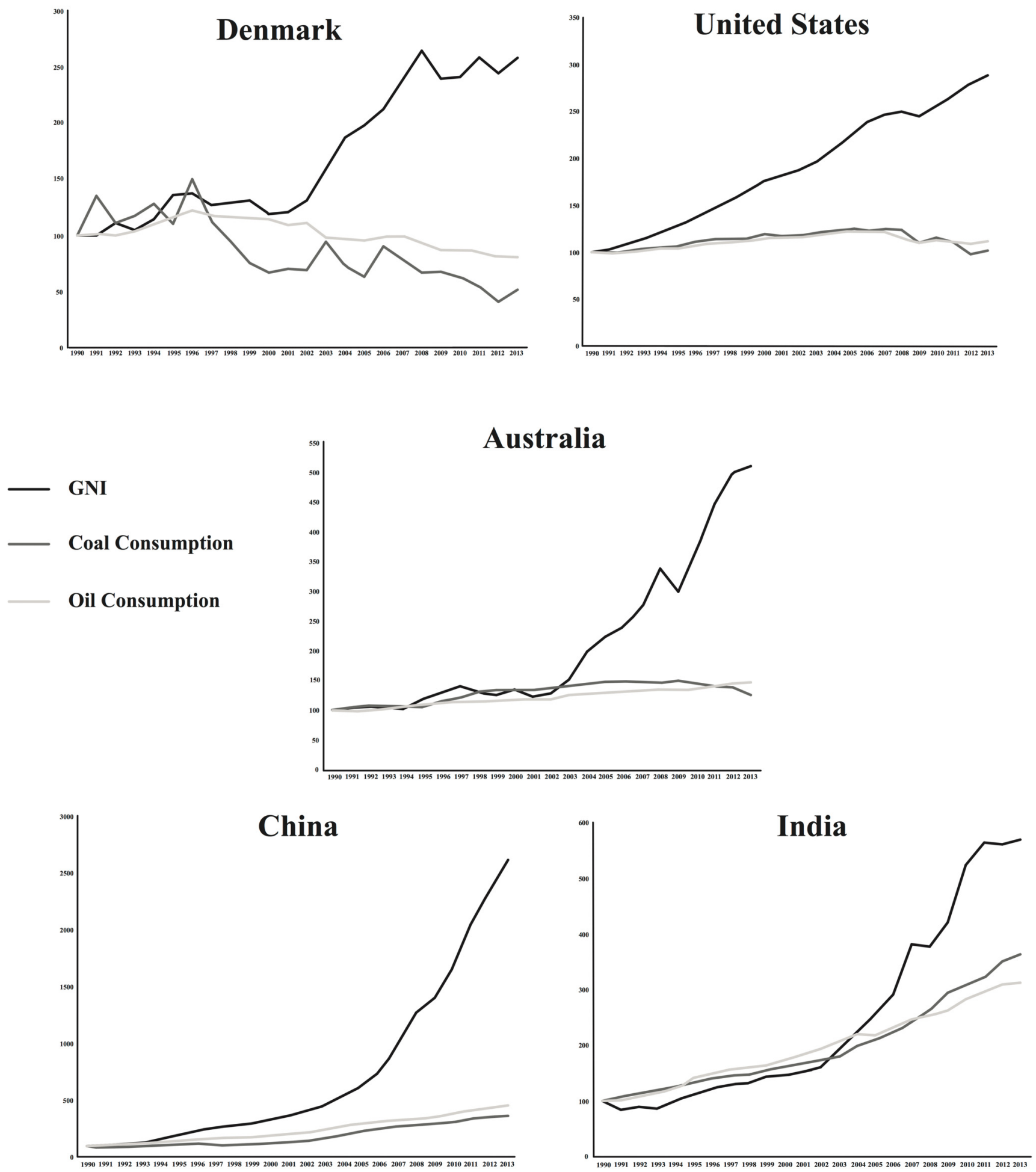

Fig. 1. The decoupling of economic growth and fossil fuel consumption in Denmark, America, Australia, China and India. GNI is Gross National Income, similar to GDP Gross National Product. Source: Authors own graphic based on data sourced from the WBG [8] and the EIA $[9,10]$. 


\subsection{The fall of coal}

\subsubsection{Structural built environment energy efficiencies}

In the period from 2000 to 2013 the Organisation for Economic Cooperation and Development improved energy efficiency by a steady $0.6 \%$ per year but in $2013 / 14$ it improved $1.5 \%$ and in $2014 / 15$ it improved $1.8 \%$ [12]. This rapid growth seems to be more structural in its base as appliances and buildings are becoming significantly more efficient as shown by the Intergovernmental Panel on Climate Change [13]. This does appear to be a demand driven process involving digital smart systems in appliances and in construction and management of buildings leading to declines in electricity consumption [14].

\subsubsection{Renewable fuel growth}

Bloomberg New Energy Finance (BNEF) has made projections of the growth in renewables based on the relative costs of fuels. They suggest that from 2015 to 2040 renewables will become the dominant power source in the world; wind and solar will account for $64 \%$ of the new generating capacity, and globally there will be $60 \%$ zerocarbon power, replacing coal and gas, which will decline from $57 \%$ to $31 \%$ [15].

The predictions are made based on trends and on declining costs for renewables relative to fossil fuels. The biggest growth is predicted to be roof top solar which will drop in cost by $60 \%$. However, it may be driven at an even faster rate if it has demand driven characteristics. Carbon tracker researchers have suggested that the changes may be even more radical than BNEF are predicting as they appear to be following more rapidly than any previous predictions and are indicating elements of disruptive innovation [16,17].

The question is therefore whether there is any new evidence of the changes being disruptive with adoption of renewables proceeding more rapidly than supply cost projections. There is evidence from Australia of a remarkably rapid adoption of roof top solar at a time when little investment in power was happening in the aftermath of abandoning the Australian carbon-pricing scheme [18]. Perth in particular showed this as the city grew rapidly in wealth over the past decade and $25 \%$ of households invested in roof-top solar photovoltaics (PV). This happened well beyond what would have been predicted based just on supply costs and household solar is now the largest power station in the grid [18]. Battery storage is now following the same trends [19] and analysis in Perth shows solar-storage systems enable over $90 \%$ gridfree electricity as well as producing more renewable energy to feed into the grid and generate income[18]. The technology of PV and batteries seems to fit into a niche for ordinary single residential householders [20]; recent demonstrations are showing similar heavy demand in medium density shared households that integrate PV and batteries using Citizen Utilities and blockchain software to enable peer to peer trading [21].

The signs are there that demand is driving the electricity system toward a rapid decline in coal even faster than supply costs would indicate. This may involve more gas in some cities like in the US where this is significantly cheaper but the attractions of roof-top solar and batteries are more than likely going to outcompete gas when the market enables it to work as it is in Australia with simple financing, permitting and installation [22,23].

\subsection{The fall of oil}

\subsubsection{Structural transport energy efficiencies}

Oil is embedded in the structure of cities through 50 years of automobile dependence in the practice of town planning; however this is changing as an unpredicted peak in car use per capita has occurred across the world's developed cities and even into emerging cities [24]. This is driven by:

- increases in density that have led to exponential declines in car use [24];

- rapid growth in transit across all the world's cities as traffic congestion has led to faster rail options that bypass the traffic [25];

- similar trends in walking and cycling driven by health considerations and the demand for better networks [26,27].

These trends are all demand driven. Vehicle efficiency has also been slowly increasing despite an increase in vehicle size washing out some of this improvement [28].

\subsubsection{Electric mobility}

Electric vehicles are growing globally at over $40 \%$ per year and are expected to reach at least $25 \%$ of the vehicle fleet by 2040 [29]. Most of this growth is in China which is likely to mean cheaper exports. The demand for electric vehicles is high whether they are personal cars, buses, trains or electric bikes and certainly with cars this is happening well before the supply cost is competitive though the daily costs of operation are significantly lower and this is a strong demand factor for most consumers; some are therefore predicting even higher adoption rates [30].

There is another demand-based trend that will impact on the shift to electric mobility. The trend in electricity to become more based on renewables means that growth in solar-powered EVs are likely to be driven by demand similar to roof top solar. EVs are already being used to fit cleverly into home PV and battery systems with the high potential for "vehicle to grid (V2G)" - transfers of power to enable extra storage options in the grid. Electric transit is also beginning to be switched to renewable power as demand for clean transport grows across cities [24] and new ways of financing this demand are being found [31].

\section{Will the demand for renewable cities rise and rise?}

The rise of the renewable city has been quite dramatic and this paper suggests that it will continue to rise due to demand which facilitates disruptive innovation in replacing both coal and oil. Such demand is seen in the improved electricity systems that are emerging as a result of the demand for roof top solar and in the demand for reurbanized cities where electric mobility can better service the needs of the community. 


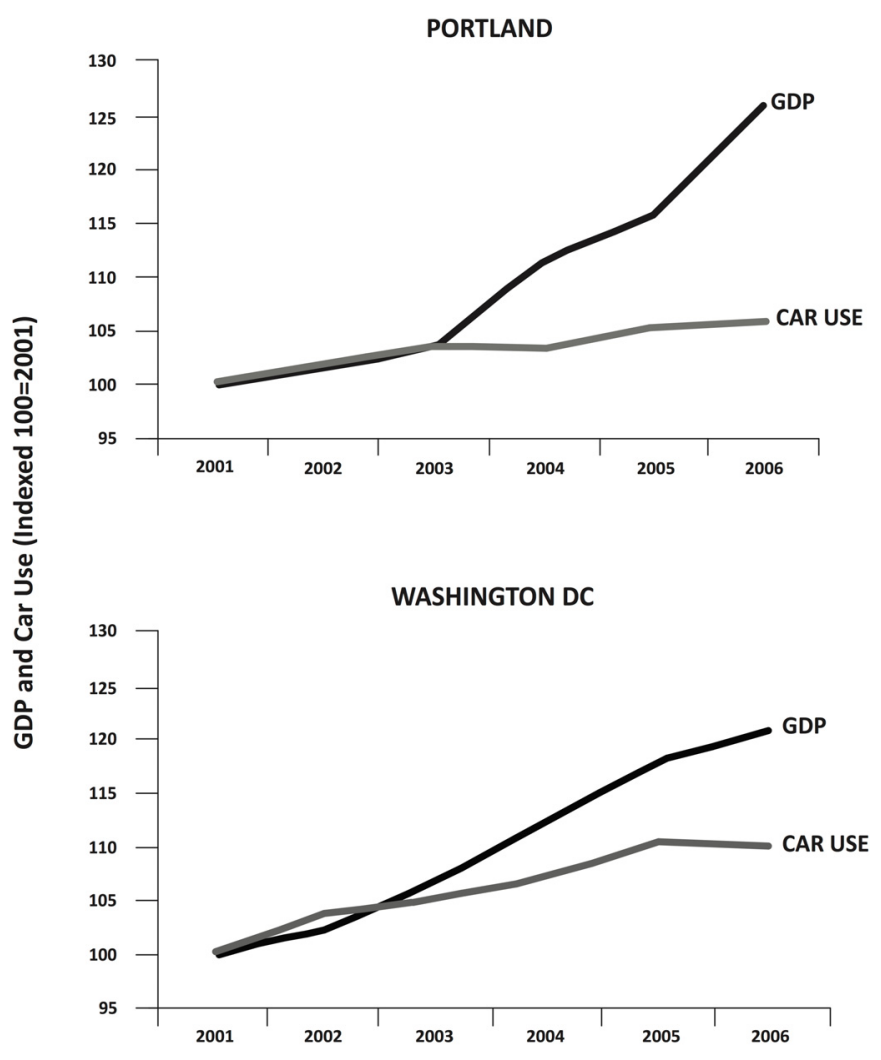

Fig. 2. Growth in decoupling car use from GDP in Washington, D.C. and Portland. Source: Authors own graphic based on data sourced from Kooshian and Winkelman [36].

There are two other demand factors that are likely to continue to drive the need for a renewable city - the knowledge economy and the digital economy.

The knowledge economy is based around creative interactions where people work together in dense urban centres as these are where the innovative, face-to-face synergies occur between people [32]. Old central business districts and new suburban centres have been transformed back into functional walking cities and those which have done this best have attracted the most capital and young talent to work there [33]. The six most walkable cities in the US have $38 \%$ higher GDP. In Boston $70 \%$ of the knowledge economy workers live in walkable locations [24].

Transit systems and walking are the most spatially efficient forms of transport as well as being the most free of carbon. If one $\mathrm{km}$ of a lane of road was considered as a unit of travel then car traffic can fit about 800 people per hour down that lane in a suburban street, a freeway up to 2500 , a busway around 5000, a light rail between 10,000 and 20,000 and a heavy rail up to 50,000 [24]. These striking differences in spatial efficiency are translating into competitive advantage based on the need to bring people together in centres. There is a strong demand for such cities because they represent the places where the new knowledge economy will most likely emerge and provide new opportunities. The data is also strong that there is demand for low carbon buildings in these new regenerating urban centres [34]. Indeed, cities are competing for residents and workers through the provision of new sustainability- oriented precincts and neighbourhoods; the data shows that sustainability features in buildings are a close third behind affordability and location $[3,32,35]$.

As with many economic changes, there is another cultural dimension to this change that perhaps explains the rapidity of the changes observed above as well as the demographic complexion of the change. Young people (especially those involved in knowledge economy jobs) are moving to reduce their car use and switch to alternative transport faster than any other group. This has been recognized by a few commentators and has been related to the use of social media devices in the digital economy. On transit or walking (and even to an extent while biking) young people are already connected by their smart technology phones and tablets. They are hardly usable while driving a car. The report by Davis et al. [34] shows that the mobile phone is a far more important device than a car for younger people. This is a cultural revolution that partly underlies the rail revolution as well as the reurbanization of cities. It is essentially a smart city phenomenon.

Thus, the structural expression of this change is that younger people are moving to live in the walking city or transit city as these locations more readily enable them to express the kind of urban experience and culture that they aspire to as well as save precious time. This is the demand that enables peak car, the rail revival and city centre renewal to continue. This can explain why cities like Washington, D.C. and Portland are demonstrating the decoupling of GDP from car use per capita (Fig. 2).

\section{Conclusion}

The evidence gathered in this paper has shown that there is a new trend: the rise of the renewable city which has emerged this century from the decoupling of fossil fuels and economic growth. The fall of coal and the fall of oil are both caused by structural energy efficiency gains (smart technology and smart buildings for coal; smart, dense transit-oriented cities that reduce car dependence for oil) and by switching to renewable fuels (coal is being replaced by wind and solar especially roof-top PV; oil is being replaced by electric mobility). This appears to be led by demand in cities as well as somewhat competitive supply costs. The rise and rise of the renewable city is thus to be expected as demand is likely to continue to rise for the urban living advantages associated with renewable city technologies and structures.

\section{References}

1. P. Droege, The Renewable City: A Comprehensive Guide to an Urban Revolution (Wiley, Hoboken, NJ, 2006)

2. P. Droege, Urban Energy Transition: From Fossil Fuels to Renewable Power (Elsevier, Oxford, United Kingdom, 2008)

3. P. Newman, T. Beatley, H. Boyer, Resilient Cities: Overcoming Fossil Fuel Dependence (Island Press, Washington, D.C., 2017) 
4. J. Green, P. Newman, Disruptive innovation, stranded assets and forecasting: the rise and rise of renewable energy, J. Sustain. Finance Invest. 7, 2 (2017), doi:10.1080/ 20430795.2016.1265410

5. C.M. Christensen, The Innovator's Dilemma: When New Technologies Cause Great Firms to Fail (Harvard Business School Press, Boston, MA, 1997)

6. T. Seba, Clean Disruption of Energy and Transportation: How Silicon Valley Will Make Oil, Nuclear, Natural Gas, Coal, Electric Utilities and Conventional Cars Obsolete by 2030 (Clean Planet Ventures, Silicon Valley, CA, 2014)

7. International Energy Agency (IEA), World Energy Outlook, Special Report on Energy and Air Quality [Report], IEA, Paris, France, 2017

8. The Worldbank Group (WBG), Total Gross National Income (GNI) - Current \$US (as of February 17, 2016), in World Development Indicators (WBG, Washington, D.C., 2016)

9. United States of America Energy Information Administration (EIA), Total annual coal consumption - thousand short tons, in Eia Beta - International: Countries Data (EIA, Washington, D.C., 2016)

10. United States of America Energy Information Administration (EIA), Total annual petroleum consumption - thousand barrels per day, in EIA Beta - International: Countries Data (EIA, Washington, D.C., 2016)

11. Author, India to meet climate goals earlier than promised says outgoing climate chief, in The Guardian (News and Media Limited, 2016)

12. Organisation for Economic Cooperation and Development (OECD), International Energy Agency (IEA), Energy Efficiency Market Report 2016 [Report], IEA, Paris, France, 2016

13. Intergovernmental Panel on Climate Change (IPCC), Climate Change 2014 Mitigation of Climate Change - Working Group III Contribution to the Fifth Assessment Report of the Intergovernmental Panel on Climate Change: Chapter 9 Buildings [Report], IPCC, Geneva, Switzerland, 2014

14. S. Nadel, R. Young, Why is Electricity use no Longer Growing? An ACEEE White Paper [Report], American Council for an Energy-Efficient Economy (ACEEE), Washington, D.C., WA, 2014

15. Bloomburg New Energy Finance (BNEF), New Energy Outlook 2016 - Long-term Projections of the Global Energy Sector: Global Overview June 2016 [Report], BNEF, New York City, NY, 2016

16. R. Schuwerk, L. Sussams, No Rhyme or Reason: Unreasonable Projections in a World of Confronting Climate Change [Report], Carbon Tracker Initiative (CTI), London, United Kingdom, 2016

17. L. Sussams, J. Leaton, Expect the Unexpected: The Disruptive Power of Low-carbon Technology [Report], Carbon Tracker Initiative (CTI), London, United Kingdom, 2017

18. J. Green, P. Newman, Citizen utilities: the emerging power paradigm, Energy Policy 105, 283 (2017), doi:10.1016/j. enpol.2017.02.004
19. B. Nykvist, M. Nilson, Rapidly falling costs of battery packs for electric vehicles, Nat. Clim. Change 5, 329 (2015)

20. P. Newton, P. Newman, The geography of solar photovoltaics (PV) and a new low carbon urban transition theory, Sustainability 5, 6 (2013), doi:10.3390/su5062537

21. J. Green, P. Newman, Planning and governance for decentralised energy assets in medium-density housing: the WGV gen Y case study, Urban Policy Res. (2017), doi:10.1080/08111146.2017.1295935

22. Carbon and Energy Markets (CME), Electricity Prices in Australia: An International Comparison - A Report to the Energy Users Association of Australia [Report], CME, Melbourne, VIC, 2012

23. S. Jarnason, Why Australian Solar Retailers can Install Residential Solar at Half the US Price (Solar Analystics, Sydney, 2016)

24. P. Newman, J. Kenworthy, The End of Automobile Dependence - Moving Beyond Car Based Planning (Island Press, Washington, D.C., 2015)

25. P. Newman, G. Glazebrook, J. Kenworthy, Peak car and the rise of global rail, J. Trans. Tech. 3, 4 (2013)

26. J. Pucher, R. Buehler, Cycling for Sustainable Transport (The MIT Press, Cambridge, MA, 2016)

27. M. Colville-Anderson, Meteoric Rise in Bicycle Traffic in Copehhagen (Copenhagenize Design Co Blog, Copenhagen, Denmark, 2016)

28. M. Sivak, B. Schoettle, What Individual Americans can do to Assist in Meeting the Paris Agreement [Report], University of Michigan Transportation Research Institute (UMTRI), Ann Arbor, MI, 2016

29. K. Carlin, B. Rader, G. Rucks, Interoperable Transit Data: Enabling a Shift to Mobility as a Service [Report], Rocky Mountain Institute (RMI), Boulder, CO, 2015

30. International Energy Agency (IEA), Global EV Outlook 2016 - Beyond One Million Electric Cars [Report], IEA and OECD, Paris, France, 2016

31. P. Newman, S. Davies-Slate, E. Jones, The entrepreneur rail model: funding urban rail through majority private investment in urban regeneration, Res. Trans. Econ. 4, 5 (2017)

32. E. Glaeser, The Triumph of the City, How our Greatest Invention makes us Richer, Smarter, Greener, Healthier and Happier (Penguin, London, United Kingdom, 2011)

33. A. Matan, P. Newman, People Cities: The Life and Legacy of Jan Gehl (Island Press, Washington, D.C., 2016)

34. B. Davis, T. Dutzik, P. Baxandall, Transportation and the New Generation: Why Young People are Driving Less and What it Means for Transportation Policy [Report], Frontier Group and PIRG Education Fund, San Francisco/Boston, CA/MA, 2012

35. J. Green, P. Newman, Demand drivers for medium density housing and the relative importance of sustainability attributes, Urban Res. Plan. (2017), doi:10.1080/ 08111146.2017.1295935

36. C. Kooshian, S. Winkleman, Growing Wealthier: Smart Growth, Climate Change and Prosperity [Report], Centre for Clean Air Policy, Washington, D.C., 2011

Cite this article as: Peter Newman, The rise and rise of renewable cities, Renew. Energy Environ. Sustain. 2, 10 (2017) 